\title{
Metal-Ceramic Smart Composite in Ti(C,N)-Ni-Mo-W System
}

\author{
Z. Kovziridze, N. Nizharadze, G. Tabatadze, E. Nikoleishvili, M. Mshvildadze \\ Department of Chemical and Biological Technologies, Georgian Technical University, Tbilisi, Georgia \\ Email: kowsiri@gtu.ge
}

Received 8 April 2016; accepted 4 June 2016; published 7 June 2016

Copyright $\odot 2016$ by authors and Scientific Research Publishing Inc.

This work is licensed under the Creative Commons Attribution International License (CC BY).

http://creativecommons.org/licenses/by/4.0/

(c) (i) Open Access

\section{Abstract}

Goal: Low wolfram-containing cutting composite was obtained by fusion of titanium carbonitride and high melting temperature binding metallic phase. Method: The composite was obtained via compaction and further sintering in vacuum furnace at $1600^{\circ} \mathrm{C}$ under $10^{-3}$ Pa pressure. Phase analysis was performed on X-ray apparatus "DRON-3"; microstructure was determined by electron microscope NANOLAB-7, microhardness by MUCKE-mark microhardness meter; relative resistance of cutters was evaluated at similar modes of cutting according to distances they passed; experiments were carried out on turning lathe. Results: Physical-mechanical characteristics of the obtained composite are: $\sigma_{\text {bend, }}=1000-1150 \mathrm{MPa}, \sigma_{\text {bend1000 }}{ }^{\circ} \mathrm{C}=600 \mathrm{MPa}, \mathrm{HV}=14 \mathrm{GPa} ; \mathrm{HV}_{1000}{ }^{\circ} \mathrm{C}=6.5$ GPa. High speeds of cutting and high temperatures resistance of cutters made by the obtained composites exceeds 1.5 - 2-folds that of cutters made of the known BK8 and KNT20 hard alloys. Conclusion: Its application is recommended in hot steel treatment by cutting, for removal of the so-called burrs, as well as in steel treatment by cutting during pure and semi-pure operations. It can also be used in jet engines, chemical industry apparatuses, electric-vacuum devices, in industry of responsible details of rockets, nuclear reactors, flying apparatuses.

\section{Keywords}

Metal-Ceramic, Composite, Cutting Material, High-Temperature, Heatproof, Micro Hardness

\section{Introduction}

Up to now the main volume of tool materials is fabricated on the base of wolfram, the reserves of which suffer gradual exhaustion. With this in view, researchers are faced with the problem to create new composite materials without wolfram or to reduce its concentration to its minimum but preserve physical-mechanical and exploitation properties inherent to the composites prepared on the base of wolfram [1]-[6]. To resolve this problem, the 
researches were in progress in many countries of the world as well as at Georgian Technical University, where the researches in this sphere were initiated by the academician T. Loladze [7]-[16]. T. Loladze contributed greatly to the development of theory of metal treatment by cutting [7]-[11].

\section{The Major Part}

As is known, cutting tools yield mainly to two types of disintegration which differ by nature: brittle and plastic [7] [17] [18]-[24]. At normal conditions of cutting a tool must not yield to deterioration of these types and must possess sufficient plasticity and brittle hardness. Brittle fracture takes place when in the cutting section, that is, in the so-called "dangerous zone" of a tool the main tensile forces reach their limiting value, the limit of strength of the material. Plastic deformation occurs when shearing force in any definite volume of a body exceeds the flow limit and contraction, intense heating and softening commence, which elevate its plasticity. It has been established that cutting tool is able to treat material if its hardness 1.4-times exceeds that of the treated material [7]. Hardness ratio should be preserved at any term of cutting, that is, even at heating of tool material.

One of the main reasons for plastic collapse of standard hard alloys is heating of contact layers and their softening in the process of cutting. Therefore, great significance is attributed to temperature dependence of hardness of tool material.

Metal-ceramic cutting composites consist of carbides, nitrides, borides or their solid solutions bound by metallic phase. The so-called ceramic phase of these composites suffers less plastic deformation. The cause of plastic deformation of cutting tools is a binding metal phase. Thus, to elevate plastic hardness we could reduce composition of metal phase, but its decrease would result in a decrease of limit of brittle hardness. Academician Loladze offered an idea [9], that one of the ways to improve cutting tools would be increase of plastic strength of metal binder. As a result of researches carried out with this in view, some composites were obtained (Table 1).

Batches were ground in vibration grinding mill for 20 - $30 \mathrm{hrs}$ in alcohol medium. After drying of suspension the powder was plasticized in rubber solution dissolved in petrol and was pressed coldly at $1 \mathrm{ton} / \mathrm{cm}^{2}$ pressure. Compressed and dried specimens were sintered at various temperatures in vacuum furnace at $1600^{\circ} \mathrm{C}$ with $50^{\circ}$-interval. After sintering the specimens were visually inspected and setting, water absorption, density and mechanical properties were determined. From the composites offered in Table 1, the best results were revealed by \#4 composite, which was subjected to further studies.

Final baking of the tested composite was performed in vacuum furnace at $1600^{\circ} \mathrm{C}$, under $10^{-3} \mathrm{~Pa}$. In the process of sintering as a result of interaction of titanium carbide and titanium nitride we received titanium carbonitride, which was confirmed by $\mathrm{X}$-ray diffraction analysis (Figure 1).

Microstructure of the tested composite is mainly homogeneous (Figure 1(a) and Figure 1(b)). The selected metal phase binds rather tightly carbonitride grains, which is confirmed by hardness limit at bending $\sigma_{\text {bend. }}=$ 1100 - $1150 \mathrm{MPa}$ (Table 2), while limit at bending of titanium carbonitride sintered at the very temperature $\sigma_{\text {bend. }}=500 \mathrm{MPa}$. Titanium carbonitride grain sizes are within $1-2 \mu \mathrm{m}$ (Figure 2). Significant impact of sintering temperature on carbonitride grain dimensions has not been fixed, which can be explained by low solubility of carbonitride in Ni-Mo-W metal phase.

Considering the fact that the hardness value is attributed a great significance for the process of cutting, harnesses were measured at room as well as at high temperatures.

Table 1. Chemical composition of batches.

\begin{tabular}{|c|c|c|c|c|c|}
\hline \multirow{2}{*}{ Batch \# } & \multicolumn{5}{|c|}{ Batch components, mass. $\%$} \\
\hline & $\mathrm{TiC}$ & $\mathrm{TiN}$ & $\mathrm{Ni}$ & Mo & $\mathrm{W}$ \\
\hline 1 & 35 & 35 & 10 & 10 & 10 \\
\hline 2 & 40 & 40 & 5 & 8 & 7 \\
\hline 3 & 45 & 45 & 5 & 2 & 3 \\
\hline 4 & 34 & 34 & 8 & 12 & 12 \\
\hline 5 & 42 & 35 & 6 & 8 & 9 \\
\hline
\end{tabular}




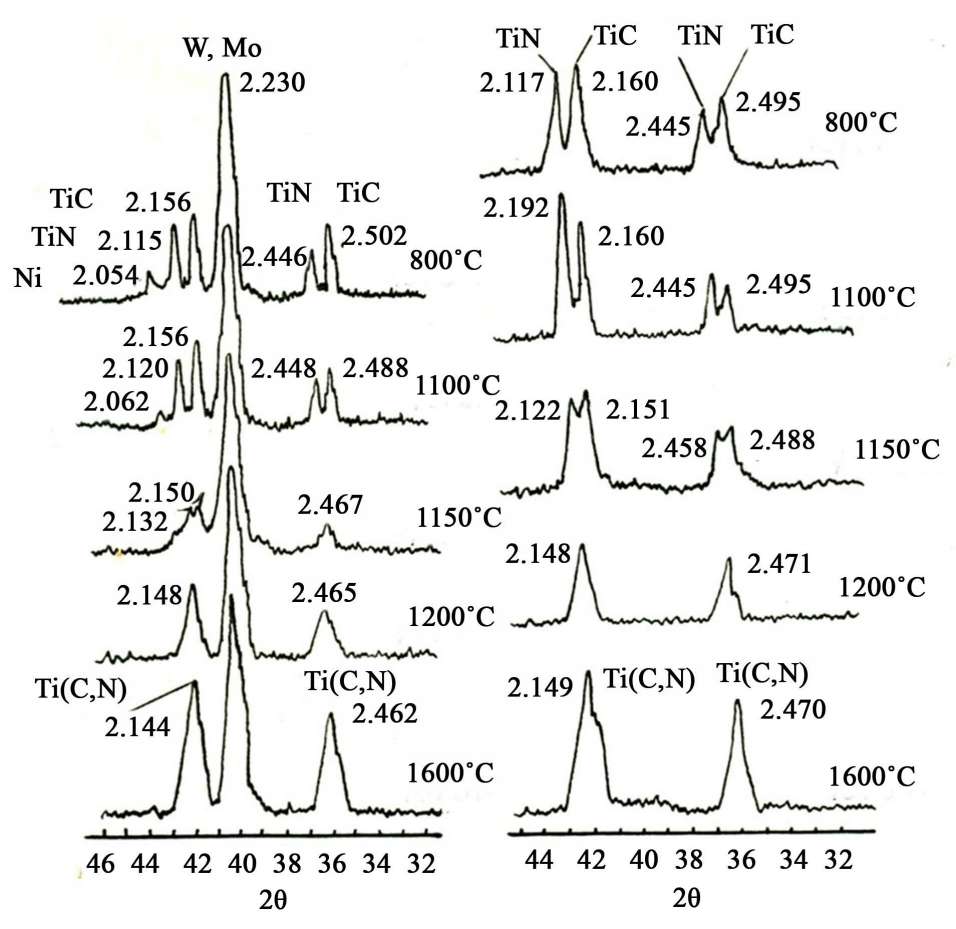

(a)

(b)

Figure 1. X-ray phase analysis of the process of sintering of low-wolfram containing tested composite: (a) in the presence of metal Ni-Mo-W phase and (b) without metal phase.

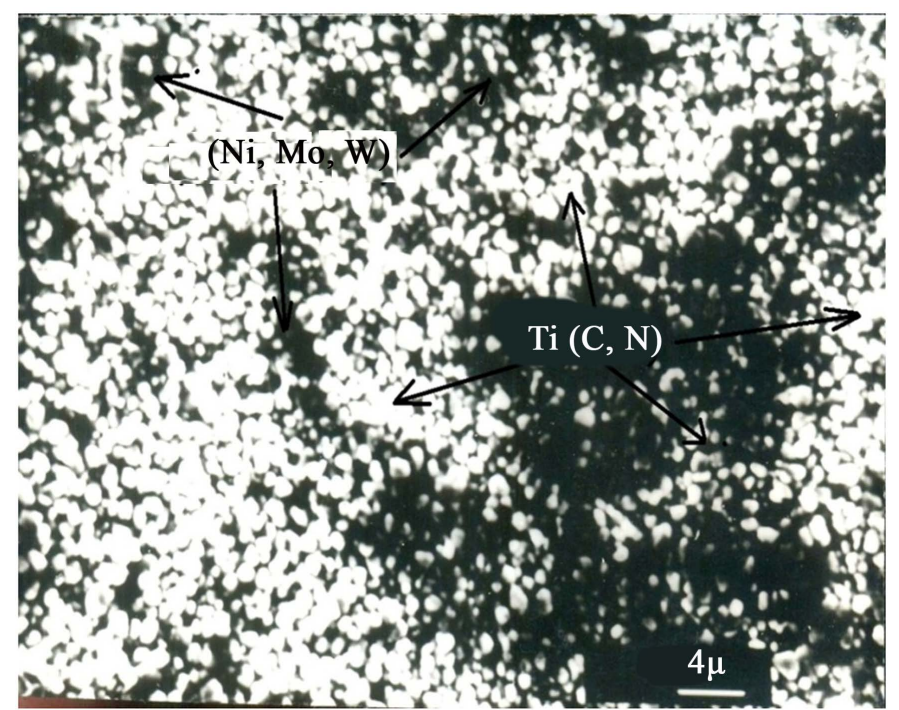

Figure 2. Microstructure of the Composite T.

Table 2. Mechanical characteristics of tested and standard composites at room temperature.

\begin{tabular}{cccccc}
\hline Composite name & $\begin{array}{c}\text { Strength at bending, } \\
\sigma_{\text {bend., MPa }}\end{array}$ & HRA & $\begin{array}{c}\text { HV, GPa } \\
\text { at 5N load }\end{array}$ & $\begin{array}{c}\text { HV, GPa } \\
\text { at 15N load }\end{array}$ & $\begin{array}{c}\text { HV, GPa } \\
\text { at 50N load }\end{array}$ \\
\hline T & $900-1150$ & $88-89$ & $9-10$ & $8-9$ & $7-8$ \\
BK8 & $1400-1500$ & $89-90$ & $10-11$ & $11-12$ & $11-12$ \\
KNT20 & $1300-1400$ & $89-90$ & $15-16$ & $16-17$ & $14-15$ \\
\hline
\end{tabular}


Hardness at room temperature was measured by Rockwell's method as well as at various loading by Vickers. Just for comparison simultaneously we measured characteristics of the standard alloys BK8 (WC92-Co 8\%); and KNT20 (TiCN80-(Ni, Mo) 20\%). Micro-hardness was measured at the Chair of Ceramics of Clausthal Technical University (Germany).

Results of measuring of micro-hardness at room temperature are offered in Table 2 and Figures 3-5.

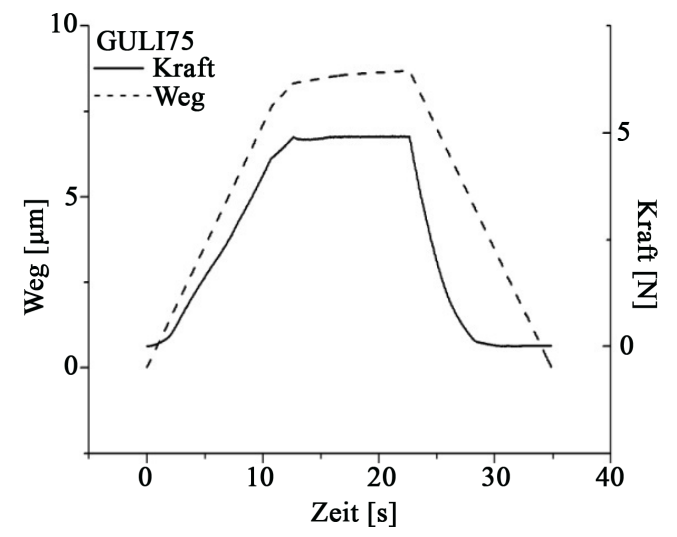

(a)

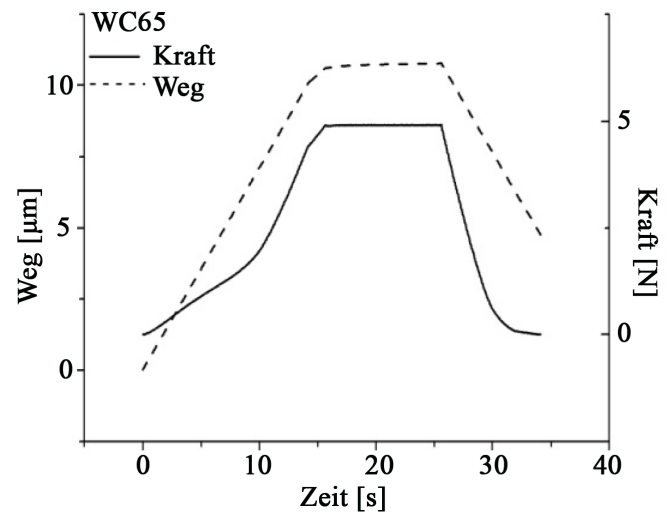

(b)

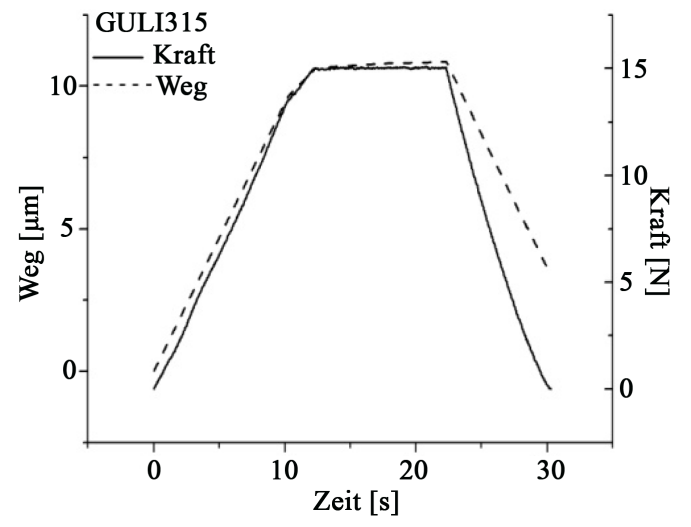

(c)

Figure 3. Graphs for micro-hardness and distance passed by indenter for $5 \mathrm{~N}$ load. (a) for tested $\mathrm{T}$ composite; (b) for BK8 and (c) for KNT20 alloys.

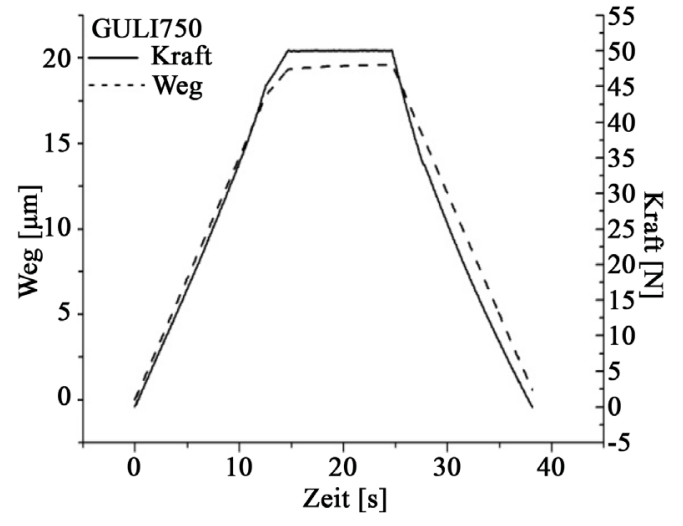

(a)

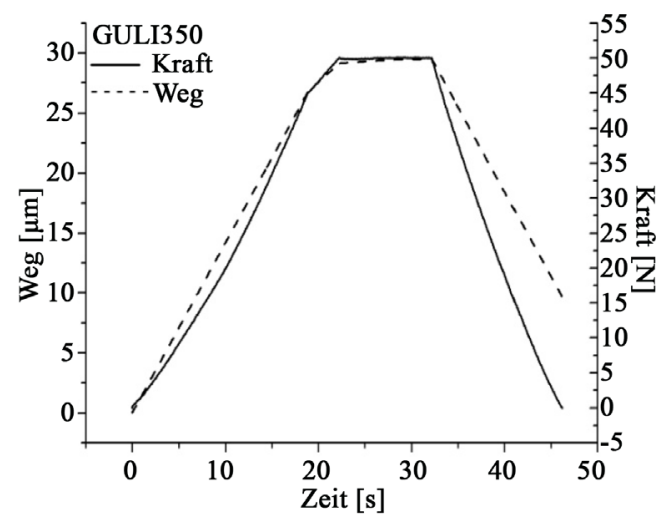

(b)

Figure 4. Graph for microhardness and distance passed by indenter for 50N load. (a) for tested T composite; (b) for KNT20 alloys. 


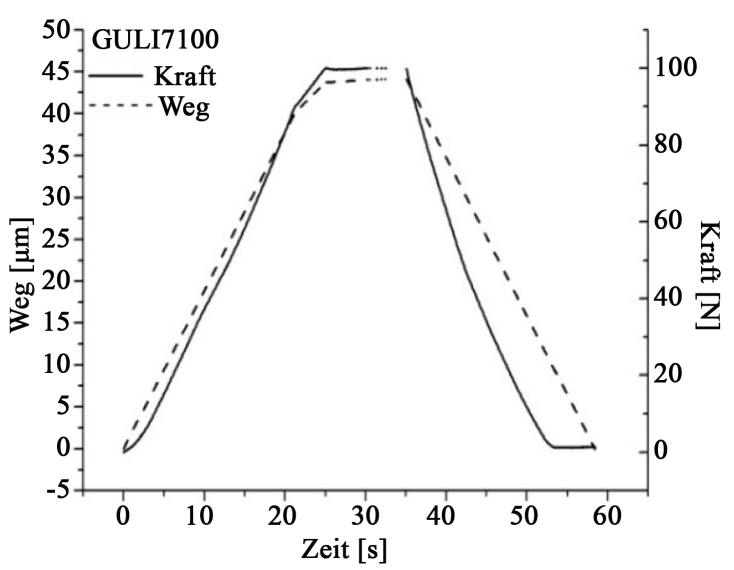

(a)

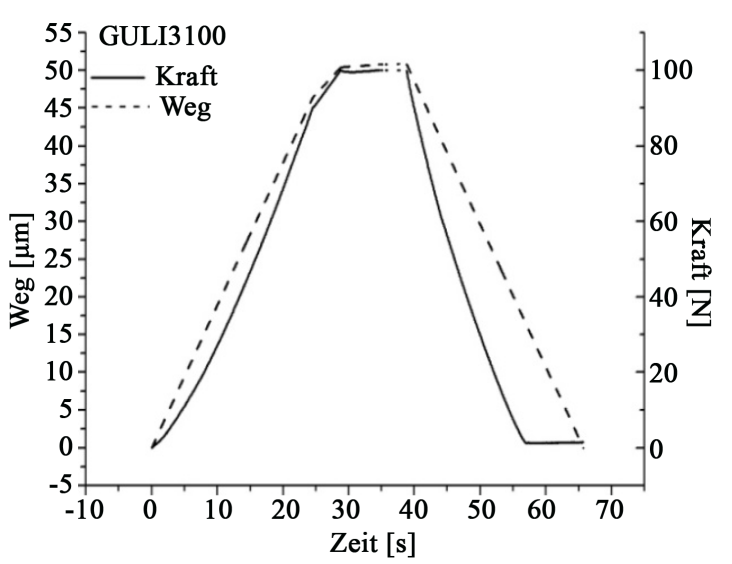

(b)

Figure 5. Graphs for micro-hardness and distance passed by indenter at $100 \mathrm{~N}$ load. (a) for tested $\mathrm{T}$ composite; (b) for KNT20 alloys.

As is seen from the Table linear relation between micro-hardness and load value was not uniquely fixed. Definite deviations are conditioned by various factors, which affect the numerical value of hardness, material non-homogeneity, grain sizes, errors at measuring and others [25]-[27].

In the process of micro-hardness measuring, with load and unload, we tried to characterize the value of flexible deformation by comparison of distance passed by an indenter, which was computed in percentages of difference between them. It turned out that for standard alloys it used to change within the limits of $22 \%-38 \%$, while for tested composite it was not fixed at all.

Consideration of indenter impression showed (Figure 6) that the limits of the tested composite are perturbed in the cases of all loading forces, while in the case of standard BK 8 fracture is fixed only after $15 \mathrm{~N}$ load and in case of KNT20 alloy, which contains $20 \%$ nickel-molybdenum metal binder, perturbation of impression limits is fixed at higher, $50 \mathrm{~N}$ loading force, which, according to our opinion refers to deficiency of flexibility deformation in tested composite, compared to standard alloys.

Determination of hardness indices at high temperatures (Table 3) prove that the tested composite preserves hardness up to a rather high temperature, while standard composites with cobalt or nickel-molybdenum metal binder are markedly inferior, and that it was conditioned by the increase of heat resistance of binding metal phase, thanks to introduction of metallic wolfram in it.

Measuring of strength at bending at high temperatures showed that strength of the tested low-wolfram composite almost doesn't suffer change up to $1000^{\circ} \mathrm{C}$, while at further increase of sample testing temperature the limit of strength at bending slowly falls, but at $1200^{\circ} \mathrm{C}$, still preserves $400-600 \mathrm{MPa}$ (Figure 7).

After investigation of specimens for strength at bending we carried out electron microscopy study for fracture (Figure 8). Case of a specimen fractured at room temperature (Figure 8(a)) shows that fault occurs via intergrain and trans-crystallite mechanism, while at high temperatures it occurs via the inter-grain metal phase (Figure 8(b)).

Results of experiments for resistance [28]-[30] of carbon, alloyed steels and thermally stable alloys at the treatment by cutting showed that resistance of tested composite exceeds 1.5 - 2-times the resistance of standard composites. (Figures 9(a)-(c)).

At the treatment of steel 45 (HRC-45) at low speeds of cutting, resistance value (Figure 9(a)) for all composites is more or less similar, and is determined according to brittle adhesive wear and tear and crumbling, since they have almost similar limit of strength. At the treatment of iron at low cutting speed $\mathrm{v}=5-10 \mathrm{~m} / \mathrm{min}$ (Figure 9(b)) resistance is approximately the same, while at $\mathrm{v}=5-10 \mathrm{~m} / \mathrm{min}$ speeds the resistance of $\mathrm{T}$ composite greatly exceeds those of BK8 and KNT20, similar is in the case of treatment of stainless steel (Figure 9(c)).

Addition of high melting temperature wolfram to metal binder of the tested composite results in increase of plastic strength of the composite and it is expressed in its advantage at cutting at high speeds [31].

Marked advantage of the tested low-wolfram composite to BK8 and KNT20 was fixed due to high plastic strength and diffuse resistance for the operations of removal of inner and external burrs of pipes welded by hot steel cutting, when cutting temperature reached $900^{\circ} \mathrm{C}-950^{\circ} \mathrm{C}$. 


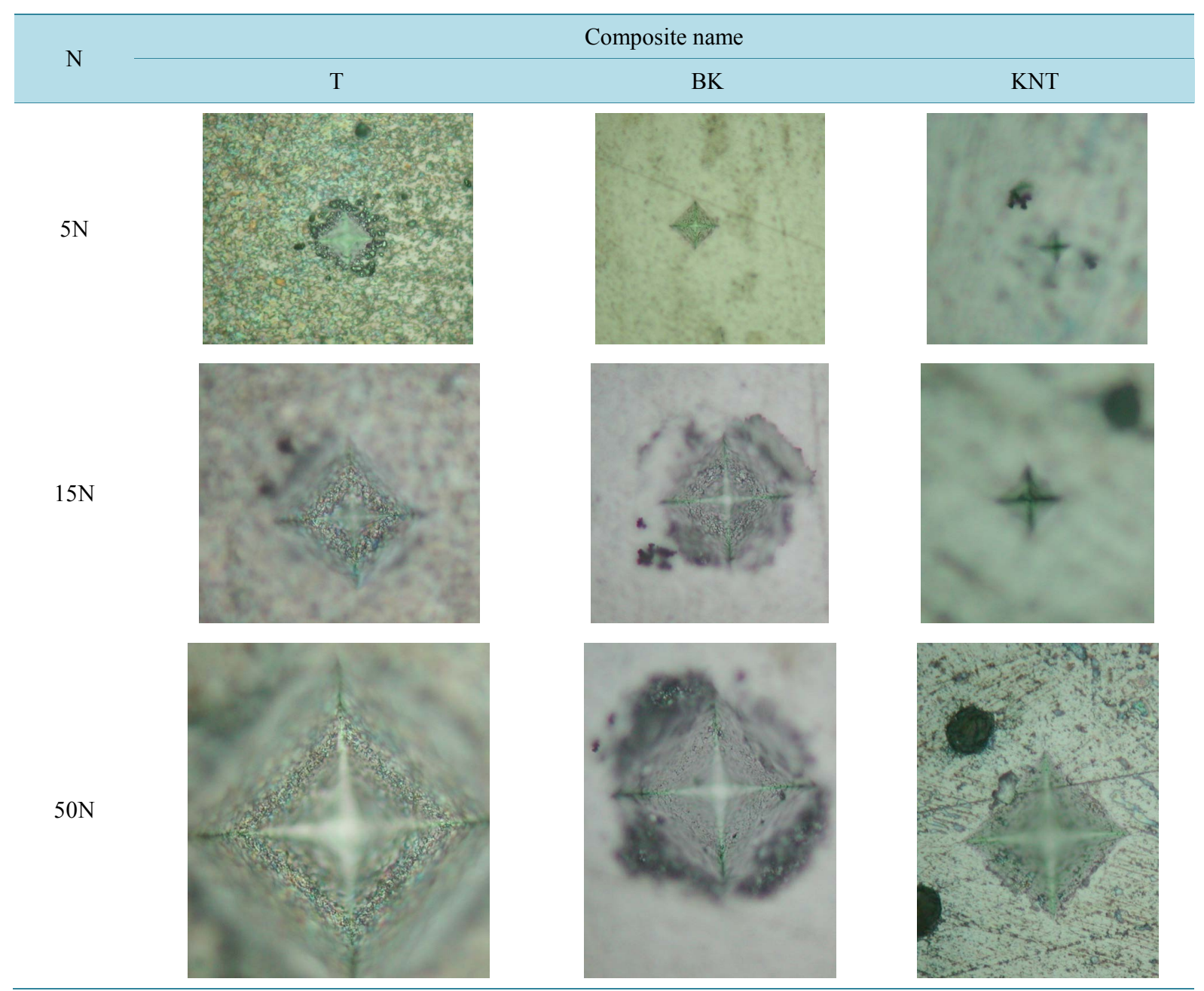

Figure 6. Indenter impression images at 5, 15, 50N loading forces.

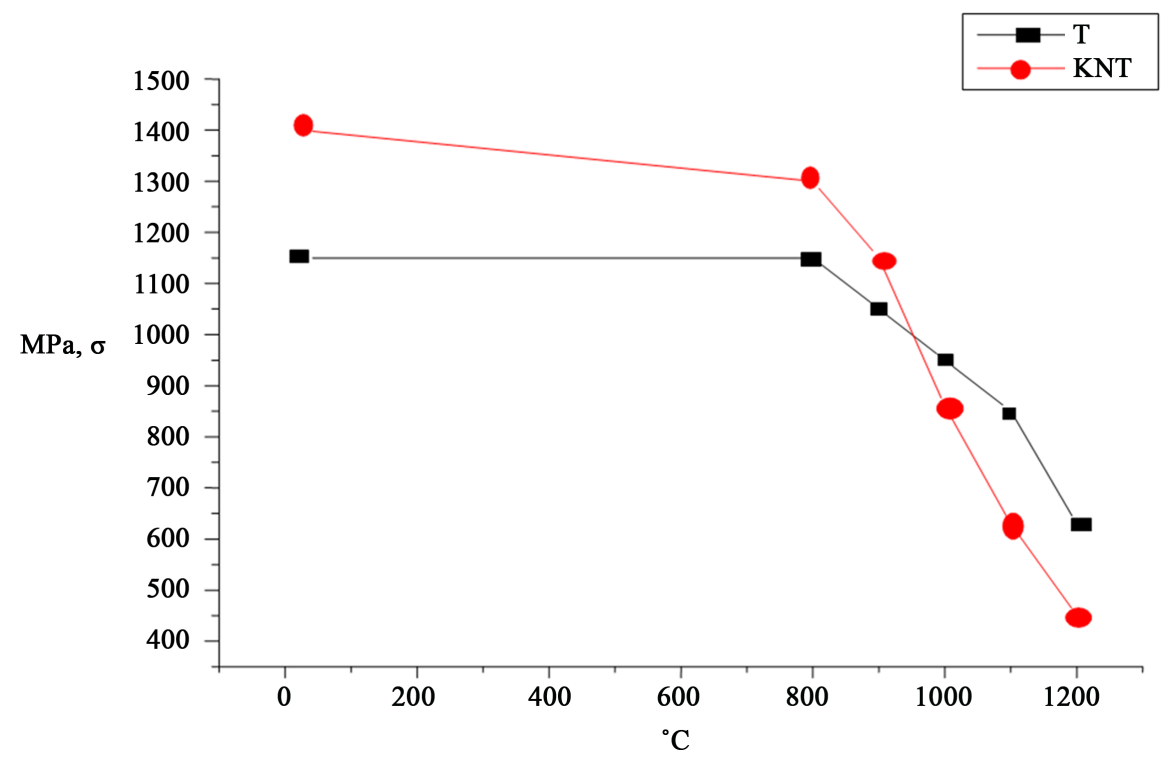

Figure 7. Curves of temperature dependence of limit of strength at bending of T and KNT 20 composites. 


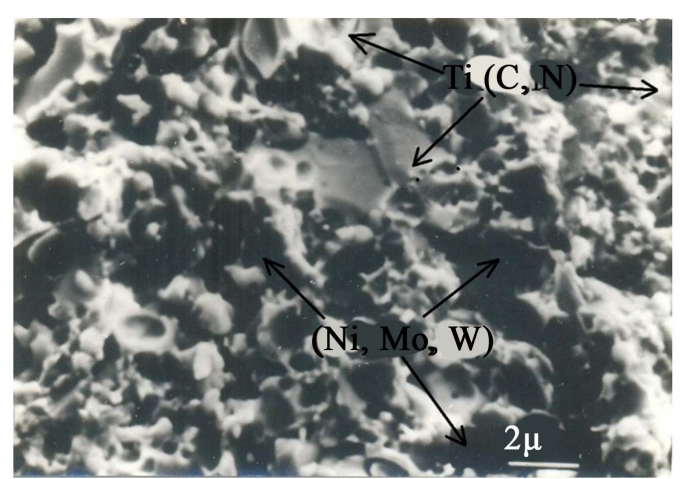

(a)

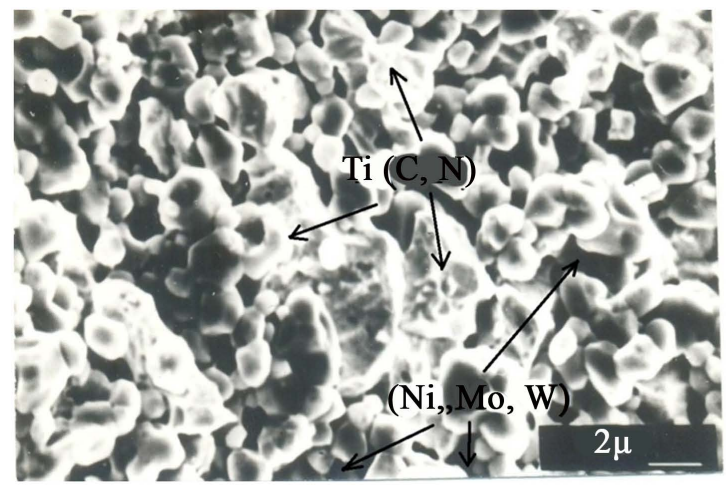

(b)

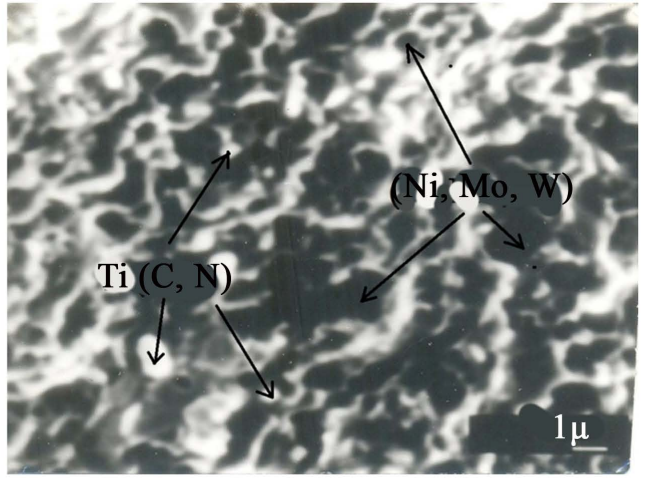

(c)

Figure 8. Electron microscopic image of $\mathrm{T}$ composite fracture after testing for limit of strength at bending: (a) at room temperature; (b) at $800^{\circ} \mathrm{C}$; (c) at $1200^{\circ} \mathrm{C}$.

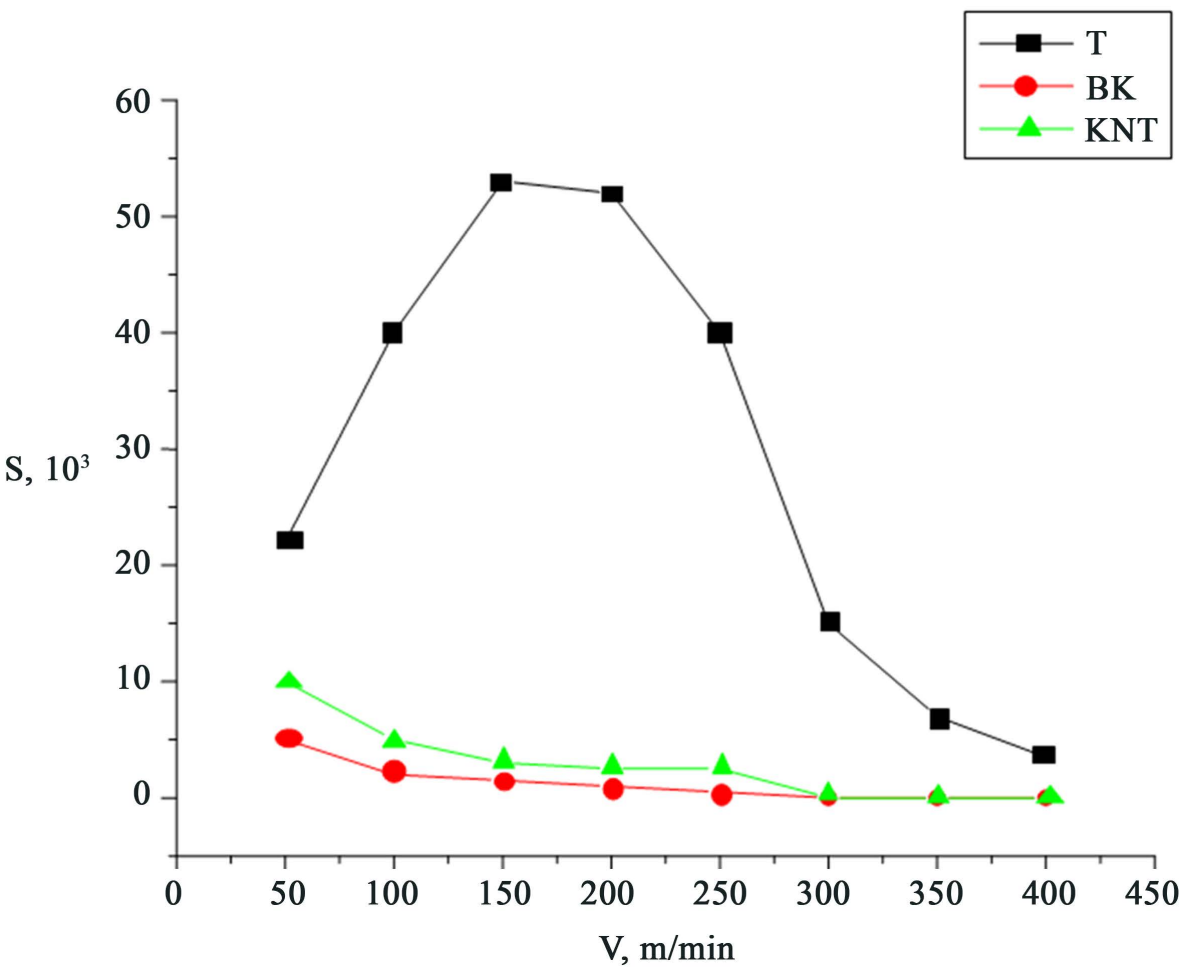

(a) 


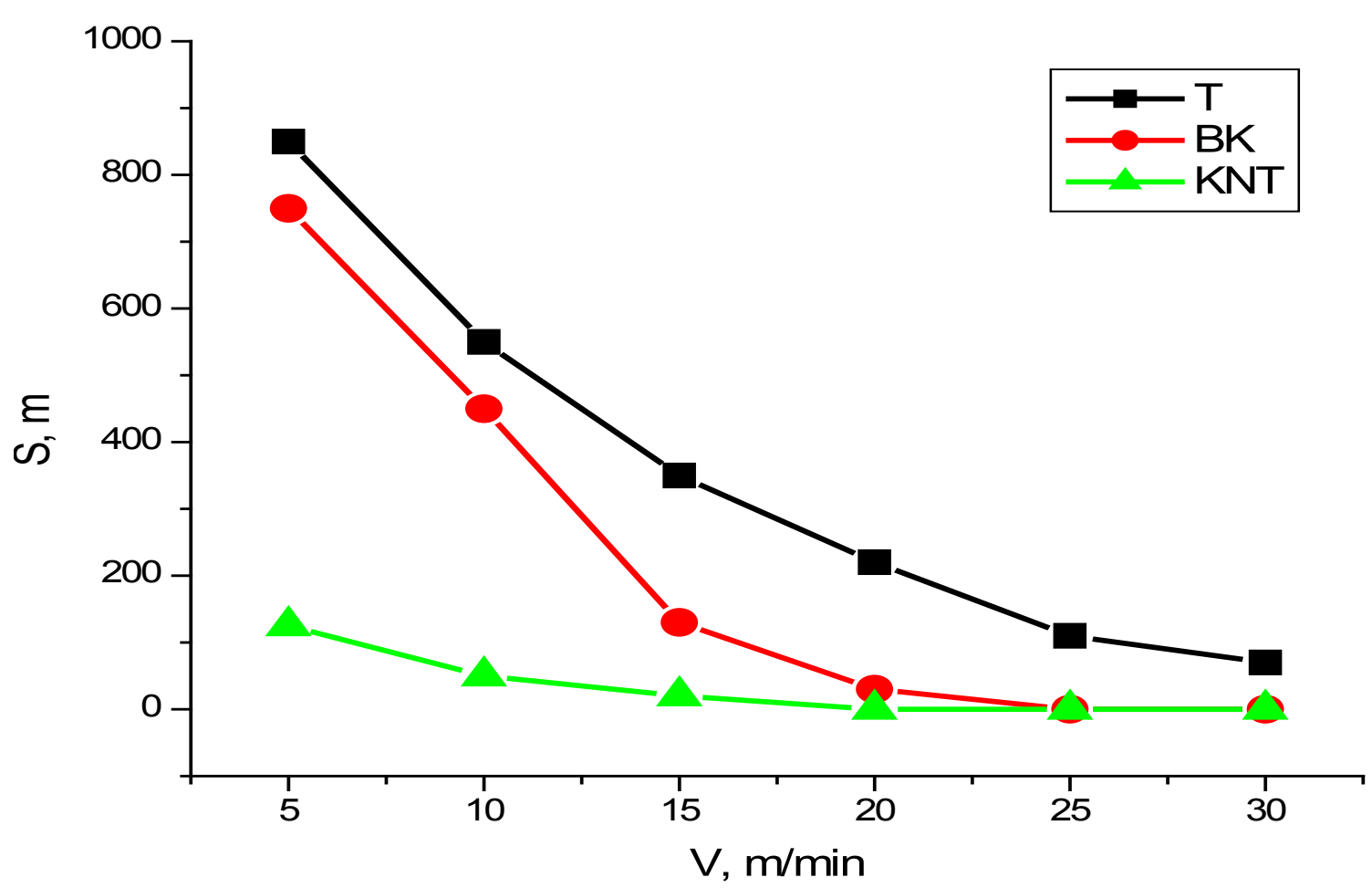

(b)

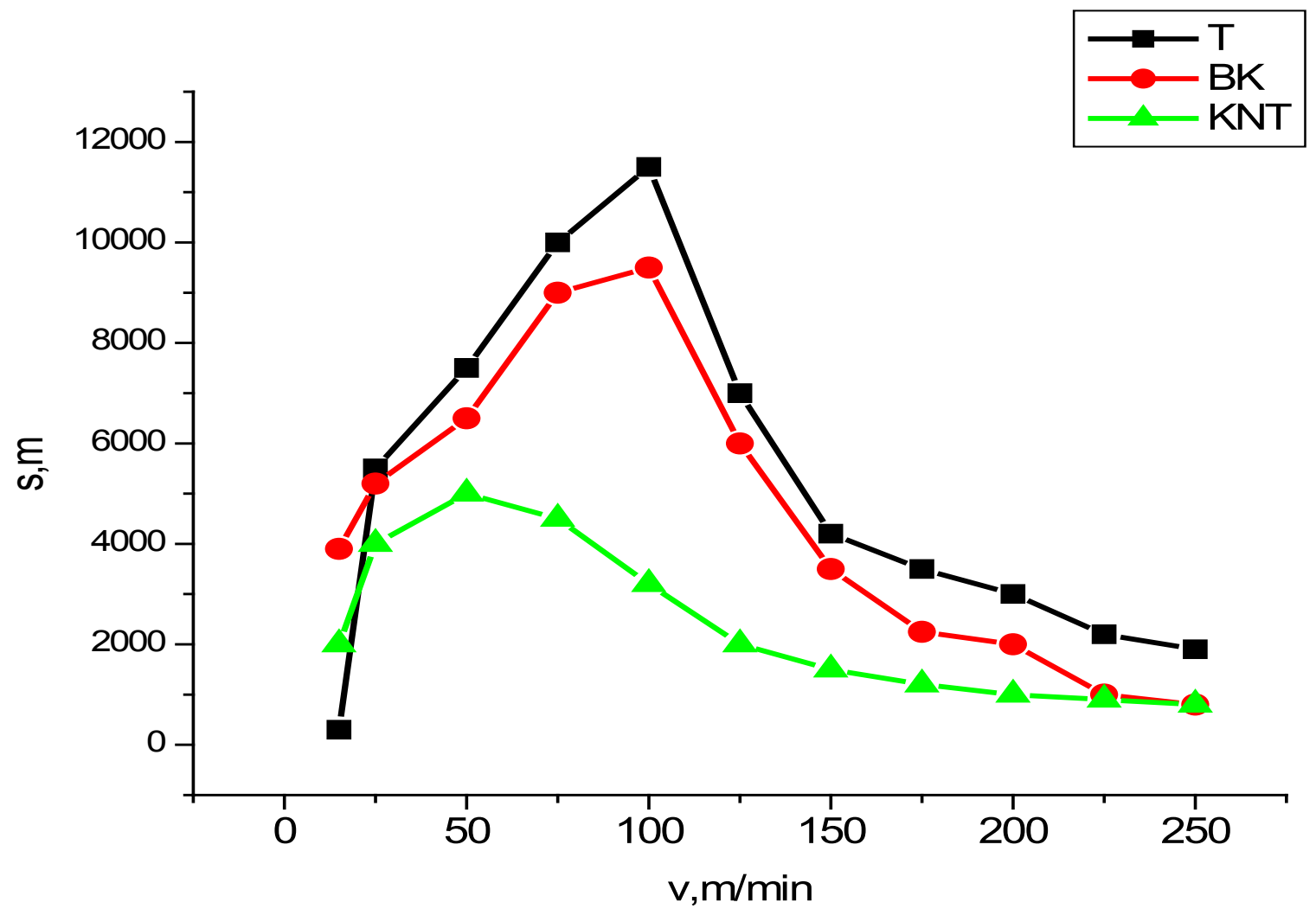

(c)

Figure 9. Curves of T, BK and KNTcomposites resistance at the treatment of various materials by cutting. (a) steel HRC = 45; (b) iron and (c) stainless steel. $\left(\alpha=\alpha=9^{\circ} ; \varphi=45^{\circ} ; \varphi_{1}=35 ; \lambda=0^{\circ} ; \mathrm{t}=1 \mathrm{~mm} ; \mathrm{S}=0.21 \mathrm{~mm} / \mathrm{rev}\right.$.). 
Table 3. Composite hardness-temperature dependence.

\begin{tabular}{cccc}
\hline Temperature & & Hardness HV, GPa & \\
$\mathrm{T}{ }^{\circ} \mathrm{C}$ & Tested T composite & WC 92-Co 8 & Ti(C, N) 80-Co 20 \\
\cline { 2 - 4 } 200 & 14.0 & 13.0 & 14.0 \\
400 & 13.0 & 10.5 & 11.5 \\
600 & 11.0 & 8.0 & 8.5 \\
800 & 9.0 & 5.5 & 6.0 \\
1000 & 6.5 & 3.5 & 4.0 \\
\hline
\end{tabular}

\section{Conclusion}

Results of the researches enable us to make conclusion that low-wolfram containing cutting composite obtained by fusion of titanium carbonitride and high melting point binding metal phase can be used at pure and semi-pure treatment of steels by cutting. Its application is recommended also in hot steel treatment by cutting, for removal of the so-called hot burrs. Besides, it can be used in jet engines, chemical industry apparatuses, electric-vacuum devices, in industry of responsible details of rockets, nuclear reactors, flying apparatuses.

\section{Acknowledgements}

We express our gratitude to the Institute of Nonmetallic Materials, Technical University Clausthal, Germany and Prof. Dr.-Ing. Jurgen G. Heinrich for the support rendered in scientific experiments.

\section{References}

[1] Shlishevsky, B.E. and Larina, T.C. (2007) Wolframfree Solid Alloys and Prospects of Their Application in Optic Sphere of Instrument Engineering. Interexpo Geo Siberia, 4, 1-7.

[2] Grubyj, S.V. (1984) Elevation of Efficiency of Lathe Treatment of Steels by Cutting Tools Made of Wolframfree Solid Alloys. Abstract of a Thesis for a Scientific Degree of a Candidate of Technical Sciences, Moscow.

[3] Zubkov, N.N. (2013) Tool Materials for Making Edge Tools. Science and Education: Electronic Scientific-Technical Edition, 75-97.

[4] Vereshchaka, A.S. and Kushner, V.S. (2009) Material Cutting. M., Vysshaya Shkola, 539.

[5] Smith, G.T. (2002) Industrial Metrology-Surfaces and Roundness. Springer-Verlag, 336.

[6] Smith, G. (2008) Cutting Tool Technology: Industrial Handbook. Springer-Verlag London Limited, London, 559.

[7] Loladze, T.N., Totchiev, F.G. and Tkemaladze, G.N. (1980) Some Features of Brittle Failure of Cutting Tools. Proceedings of the International MTOR Conference, Swancea, 297-303.

[8] Loladze, T.N. (1982) Durability and Wear Resistance of Cutting Tools. M., Machine Building, 320.

[9] Loladze, T.N. (1980) Major Directions of Development of Metalworking by Cutting. Herald of Machine Building, No. $11,40-41$.

[10] Mikanadze, A.I. (1983) Cutting Properties and Application of Low Wolfram Alloys with High Temperature Bonds. Abstract of a Candidate's Thesis, Georgian Technical University, Tbilisi, 30.

[11] Loladze, T.N. (1977) Scientific Bases for Creation of Efficient Tool Materials on the Base of T and TP Alloys. Abstracts of Reports of All-Union Symposium: Problems of Creation and Inculcation of Highly Efficient Cutting Tool with Reduced Wolfram Concentration, Tbilisi, 57-69.

[12] Kowsiridze, Z., Kiknadze, N., Hainrich, J., Goerke, R. and Tabatadze, G. (2010) Structural Research of $\mathrm{Al}_{2} \mathrm{O}_{3}$-TiC System Nanoceramic Composite Material. The First International Conference for Students and Young Scientists on Materials Processing Science, Tbilisi, 10-13 October 2010, 66-72.

[13] Kowsiridze, Z., Nizharadze, N., Tabatadze, G., Nikoleisvili, E., Mestvirisvili, Z. and Kinkladze, V. (2011) Multifunctional Heteromodulus Composites in the $\mathrm{B}_{4} \mathrm{C}-\mathrm{BN}-\mathrm{TiC}-\mathrm{SiC}-\mathrm{C}$ System. Journal of the European Ceramic Society, 31, 1921-1926.

[14] Kowsiridze, Z., Jalabadze, N. and Tabatadze, G. (2012) $\mathrm{B}_{4} \mathrm{C}$ and $\mathrm{Al}_{2} \mathrm{O}_{3}$ Based Composites. The 2nd International Conference for Students and Young Scientists on Materials Processing Science, Tbilisi, 10-13 October 2012, 150-156. 
[15] Kowsiridze, Z., Kiknadze, N. and Tabatadze, G. (2012) Cutting Ceramic Composite material on the $\mathrm{Basis}$ of $\mathrm{Al}_{2} \mathrm{O}_{3^{-}}$ TiC-WC-TiN System. The 2nd International Conference for Students and Young Scientists on Materials Processing Science, Tbilisi, 10-13 October 2012, 136-141.

[16] Kowsiridze, Z., Tabatadze, G., Hainrich, U. and Mestvirisvili, Z. (2012) Improvement of Boron Carbide Mechanical Properties in B4C-TiB2 and B4C-ZrB2 System. The 4th International Congress on Ceramics, Chicago, 15-19 July 2012, 65.

[17] Loladze, T.N. (1976) Principles for Creation of Efficient Tool Materials for Refractory Alloys and Special Steels. Georgian Polytechnic Institute, Tbilisi, 44.

[18] Postnev, V.V., Khadiullin Shafikov, A.A. and Fedorovtsev, Y.A. (2010) Study of the Influence of Intensity Auto Vibration on the Stability of the Form of Hard-Alloy Tools Cutting Edge. Herald of Ufa State Technical University, 14, 43-49.

[19] Trefilov, V.I. and Milmann, Y.A. (1984) Inorganic Materials. Proceedings of the USSR Academy of Sciences, 20, 958966.

[20] Trefilov, V.I. and Milmann, Y.A. (1975) Physical Bases of Durability of Refractory Metals. Naukova Dumka, Kiev.

[21] Andrievsky, R.A.J. (1979) All-Union Physical Society, No. 3, 258-262.

[22] Andrievsky, R.A., Lanin, A.G. and Rymashevsky, G.A. (1974) Durability of Refractory Substances. Metallurgy, Moscow, 231.

[23] Andrievsky, R.A. and Spivak, I.I. (1989) Durability of Refractory Substances and Materials on Their Base. Reference Book, Metallurgy, Chelyabinsk Branch, Chelyabinsk, 367.

[24] Lipatov, A.A. and Chigirinsky, Y.L. (2012) Evaluation of Cutting Properties of Refractory Tools according to Volumetric Concentration of Phases. Proceedings of Volgograd State Technical University, 13, 35-37.

[25] Fedosov, S.A., Lomonosov, M.V. and Peshek, L. (2004) Determination of Mechanical Properties of Materials by Means of Micro Indenting. Moscow State University, Moscow, 98.

[26] Golovin, Y.I. (2009) Nanoindenting and Its Opportunities. Machine Building, Moscow, 312.

[27] Matjunin, V.M. (2006) On-Line Diagnostics of Mechanical Properties of Construction Materials. MEI, Moscow, 214.

[28] Makarov, A.D. (1981) Accelerated Methods for Determination of Optimal Cutting Regimes. In: Interuniversity Collection of Scientific, Ed., Optimization of Regimes of Cutting of Heat Resistant and Special Refractory Materials, No. 6 , Ufa, 3-16.

[29] Kovelenov, Y.N., Mikhailov, S.V. and Bolotskikh, S.V. (2014) Development of Experimental Method of Accelerated Determination of Cutting Properties of Tools. Proceedings of Samara Scientific Center "RAN", 16, 404-409.

[30] Artamanov, E.V., Vasikega, D.S. and Tveryakov, A.M. (2013) Determination of Maximum Temperature of Operation of Insert Technology Made of Solid Tool Alloys. Journal of Omsk Scientific Herald, 123, 85-87.

[31] Trefilov, V.I., Grigoriev, O.N. and Shatokhin, T.M. (1981) Reports of Proceedings of the USSR Academy of Sciences. ДАН СССР, Vol. 2. 